\title{
Isolation and Analysis of Methanol Extract of Leaf of Senna siamea
}

\author{
V. M. Balami ${ }^{1}$, J. Yakubu ${ }^{1}$, U. T. Mamza ${ }^{1}$, S. I. Dawa ${ }^{1}$, F. I. Abdulrahman ${ }^{1}$ and O. A. Sodipo ${ }^{2}$ \\ ${ }^{1}$ Department of Pure and Applied Chemistry, Faculty of Science, University of Maiduguri, Maiduguri, \\ Borno State, Nigeria. \\ ${ }^{2}$ Department of Clinical Pharmacology and Therapeutics, College of Medical Science, University of \\ Maiduguri, Maiduguri, Borno State, Nigeria. \\ *Corresponding author Email: bmusavictor@yahoo.com, +2348066322932 \\ Received 16 April 2020; accepted 10 September 2020, published online 30 October 2020
}

\begin{abstract}
This study aimed at isolation and characterization of biochemical constituents of the leaf extract of Senna siamea. The fresh leaves of Senna siamea were air-dried, pulverized and extracted using methanol by maceration method. The extract was screened for phytochemicals using standard methods. Fifty grammas (50 g) of the crude extract was defatted using n-hexane; $20 \mathrm{~g}$ was subjected to column chromatographic (CC) analysis using ethyl acetate and n-butanol fractions with similar retardation factor $\left(\mathrm{R}_{\mathrm{f}}\right)$ were pooled and coded. Subsequently purification of fraction $\mathrm{SSM}_{5}$ was carried out using CC with solvent [Toluene and n-butanol (4:1) as mobile phase]. The collection was based on colour bands) and TLC was carried out where a sub-fraction $\mathrm{SSM}_{54}$ amongst other fractions gave a single spot on TLC and the $\mathrm{R}_{\mathrm{f}}$ value was 0.71 . It was then subjected to UV, IR and GC-MS analysis. The extract by maceration yielded $12.60 \% \mathrm{w} / \mathrm{w}$ and the defatted extract yielded $10.0 \% \mathrm{w} / \mathrm{w}$. The result of the UV-visible gave a wavelength of $289 \mathrm{~nm}$ and an absorbance of 4.268. The result of infrared spectroscopy revealed functional groups thus $\mathrm{O}-\mathrm{H}, \mathrm{N}-\mathrm{H}, \mathrm{C}-\mathrm{H}$ stretching group at $3385.8 \mathrm{~cm}^{-1}$, -CHO at $2955.8 \mathrm{~cm}^{-1}$, - $\mathrm{CHO}$ stretching at $2926.0 \mathrm{~cm}^{-1},-\mathrm{NH}_{3}{ }^{+}$at 1640.0 $\mathrm{cm}^{-1}$, carboxylate ion $-\mathrm{CO}_{2}^{-}$for amino acid at $1449.9 \mathrm{~cm}^{-1},-\mathrm{N}=\mathrm{N}-$ at $1401.5 \mathrm{~cm}^{-1},-\mathrm{N}^{+} \mathrm{O}^{-}=\mathrm{N}-$ at $1315.8 \mathrm{~cm}^{-}$ ${ }^{1}, \mathrm{C}-\mathrm{O}-\mathrm{C}$ at $1189 \mathrm{~cm}^{-1}$, Si-O at $1084 \mathrm{~cm}^{-1}$ and $\mathrm{S}=\mathrm{O}$ at 1013.8. The GC-MS analysis of $\mathrm{SSM}_{54}$ revealed the presence of Diisoctyl phthalate, Purine-2,6-dione, 8-(3-Ethoxypropylamino)-1,3-dimethyl-3, 9-dihydro-, a-Pinene, 10-(dimethylaminomethyl), 1H-indene-2-ethanamine, $\mathrm{N}, \mathrm{N}$ - dimethyl-3-[1-(2-pyrindinyl) ethyl] -, Benzene, 1, 2- bis(2,5 dimethylphenylaminomethyl)-3,6- dimethyl- and Cinnamic acid, p(trimethylsiloxy)-, methyl ester were among the probable bioactive compounds.

Key words: Senna siamea, Chromatographic, Gas Chromatography-Mass Spectroscopy, Ultraviolet Visible Spectroscopy and Infrared Spectroscopy
\end{abstract}

\section{Introduction}

The use of plants as medicines pre-dates written history. The earliest records of herbs are found from the Sumerian civilization, where hundreds of medicinal plants, including opium, were listed on clay tablets. Over the years they have assumed a central stage in modern civilization as natural source of chemotherapy as well as amongst scientists in search for alternative sources of drugs. About 3.4 billion people in the developing world depend on plant-based traditional medicines. This represents about 88\% of the world's inhabitants, who rely mainly on traditional medicine for their primary health care. [1]

In 2001, researchers identified 122 compounds used in modern medicine derived from traditional plant sources; $80 \%$ of these have had a traditional use identical or related to the current use of the active elements of the plant [2]. These include the common drugs aspirin, digoxin, quinine and opium [1]. The compounds found in plants are of many kinds, but most are in four major biochemical classes; the alkaloids, polyphenols, glycosides and terpenes. These classical biocompound found in plants are called phytochemical.Without specific knowledge of their cellular actions or mechanisms, phytochemicals have been considered possible drugs for millennia [1]. For example, salicin, having anti-inflammatory and pain-

relieving properties, was originally extracted from the bark of the white willow tree and later synthetically produced to become the common, over-the-counter drug, aspirin [3,4]. The carotenoids, beta-carotene, alpha-carotene and beta-cryptoxanthin, however, are well- 
established as provitamin, a compounds essential for normal growth and development, immune and vision [5]. Other carotenoid phytochemicals, such as lycopene, lutein and zeaxanthin, are not yet fully understood for their possible nutritional or biological effects [5].

Chromatography is the collective term for a set of laboratory techniques for the separation of mixtures. The technique has been vastly employed by organic chemist for the isolation of natural products, The involved in the mixture is being dissolved in a fluid called the mobile phase, which carries it through a structure holding another material called the stationary phase. The various constituents of the mixture

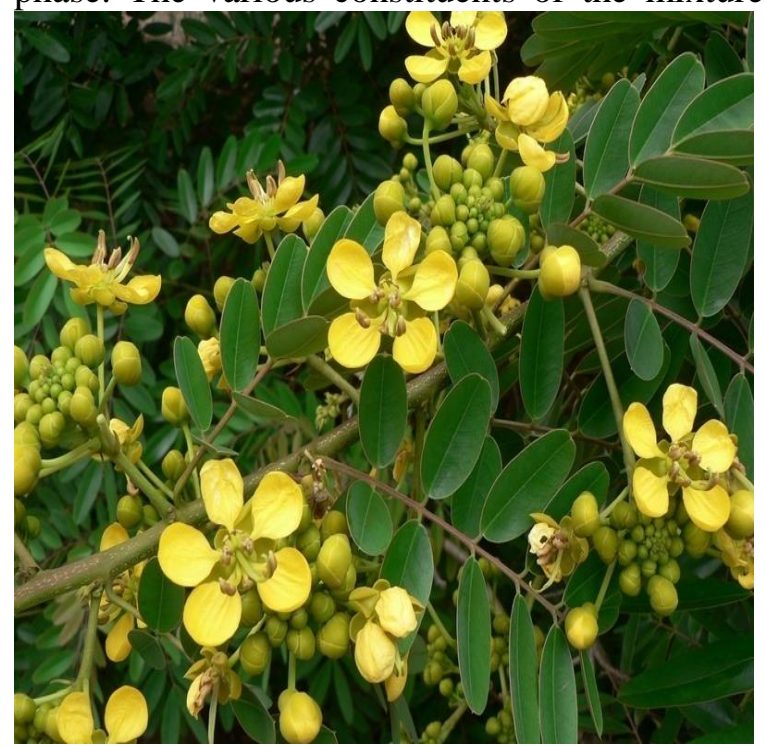

Fig. 1: Picture of the leave

\section{Materials and Methods \\ Sample Collection, Identification and Extraction}

Fresh sample of the leaf of Senna siamea was collected from Faculty of Veterinary Medicine, University of Maiduguri, Maiduguri, Borno State, Nigeria. The Plant material was identified and authenticated by a Plant Taxonomist Prof S.S. Sanusi, Department of Biological Sciences, University of Maiduguri, Borno State, Nigeria to be from Senna siamea, deposited at the of the Postgraduate Research Laboratory, Chemistry Department, University of Maiduguri, Maiduguri with voucher number of 549Awas given. The fresh plant sample was cleaned and travel at different speeds, causing them to separate. The separation is based on differential partitioning between the mobile and stationary phases. Subtle differences in a compound's partition coefficient result in differential retention on the stationary phase and thus changing the separation [6].

Senna siamea is a common plant in the Northeast of Nigeria, but in spite of its uses in traditional medicine by the local people in the northeast of Nigeria, only a few scientific studies have been carried out with little documentation on its isolation and characterization to identify the possible bioactive compounds it has. This study reports its isolation and identifying possible bioactive compound(s) in the plant. air-dried under shade at room temperature for two weeks [7].

\section{Isolation of biochemical constituents of Senna siamea \\ Column Chromatography (CC)}

The defatted methanol crude extract was subjected to Column Chromatographic separation to further purify a bioactive compound. Twenty $20 \mathrm{~g}$ of the defatted crude extract was used for the Column Chromatographic study solvents system of ethylacetate and n-butanol in various combining ratio as 100:0, 80:20, 60:40, 50:50, 40:60, 20:80 and $0: 100$ respectively. 
A glass tube with a diameter $2.8 \mathrm{~cm}$ and a height of $90 \mathrm{~cm}$ with a tap at the bottom was used for the column chromatography. A plug of cotton wool was well placed at the bottom of the column very close to the tap so as to prevent the stationary phase from blocking the column. Eighty $80 \mathrm{~g}$ of silica gel 60-120 mesh (Quikelem, India) was used to prepare slurry by wet method. The silica gel was mixed with nhexane and stirred with a clean glass rod until a uniform mixture was obtained, then it was packed cautiously and manually to two third the size of the column tube using a glass funnel. The gel was then allowed to settle and pack for 24 hrs. The air bubbles were avoided and care was taken not to dry the column by maintaining the level of the chloroform to that of the silica gel. $20 \mathrm{~g}$ of the mixture of the defatted ethanol crude extract and $5 \mathrm{~g}$ of silica gel in methanol was mounted on the already equilibrated silica-fixed column on top of the stationary phase. This was topped with a small layer of cotton, then sand to protect the shape of the organic layer from the velocity of newly added eluent (stationary phase). The eluting solvent initially was $100 \%$ ethyl acetate and the polarity was gradually increased at 90:10, ethyl acetate: n-butanol ratio until 0:100 ethyl acetate: n-butanol ratio was used. Twenty two (22) sub-fractions were collected. The fractions collected were monitored using TLC plate. Those with similar $\mathrm{R}_{\mathrm{f}}$ were pooled together, at the end five (5) portions were obtain from the pooling process coded as $\mathrm{SSM}_{1}$ to $\mathrm{SSM}_{5}$ respectively, the column chromatographic procedure stated above

\section{RESULTS}

\section{Extraction and Defattening Profile of Senna siamea Leaf}

The extraction of the leaf of Senna siamea using methanol produced extract with dark green colour. The methanol extract had the mass of $63.0 \mathrm{~g}$ and the percentage yield of $12.6 \%$. The result of the extraction profile is shown on Table was applied to portion $\mathrm{SSM}_{4}$ and $\mathrm{SSM}_{5}$. This method was used to further purify the column fractions using Toluene and n-butanol in increasing polarity as mentioned above until a compound of single spot on thin layer chromatography was achieved.

Thin Layer Chromatography (TLC)

Commercially prepared aluminium back TLC plates of $20 \times 20 \mathrm{~cm} \times 0.25 \mathrm{~mm}$ activated silica gel of $60 \mathrm{~F}_{254}$ (Merck, Germany) was cut to size of $5 \times 5 \mathrm{~cm}$. Methanol leaf extract of Sennasiamea which contained the most phytochemicals and had the largest quantity was preferred for the chromatographic analysis. Methanol was used to dissolve the extract and allowed to stand for 30 minutes and then it was spotted at the bottom of the TLC plate $(1.5 \mathrm{~cm}$ from the base).

The extract which was dissolved in a few drops of methanol was dried in air for 30 minutes and was used for the spotting by the aid of a capillary tube. The spotted plate was placed in a previously saturated developing chamber containing toluene and ethyl acetate in ratio 4:1 the chosen solvent system as mobile phase and was covered with a watch glass and allowed to run 3/4th of the height of the prepared plates (8). Fractions which gave a single spot when developed, using the chromatographic tank was allowed to dry. The Retention Factor $\left(R_{f}\right)$ values of the compounds (pure) measured and then crystallize, was recorded prior to elucidation of possible structures by Gas Column-Mass Spectroscopy (GC-MS).

1. The methanol extract $(50 \mathrm{~g})$ which was defatted using n-hexane produced extracts with dark green and brown colour of gummy masses respectively. The crude methanol leaf extract with initial weight of $50 \mathrm{~g}$ yielded of $10.0 \%$. The result of the extraction profile is shown on Table 2

Table 1: Extraction profile of air-dried powdered leaves of Senna siamea

S/N Fraction Mass $(\mathrm{g}) \quad \%$ Yield $\left({ }^{\mathrm{w}} / \mathrm{w}\right) \quad$ Colour Texture

$\begin{array}{llll}\text { 1. Methanol } & 63.00 & 12.60 & \text { green }\end{array}$ 
J. Chem. Soc. Nigeria, Vol. 45, No.6, pp 1110 - 1119 [2020]

Table 2: The profile of Senna siamea methanol crude extract defatted portion

\begin{tabular}{llllll}
\hline S/N & Fraction & Mass $(\mathrm{g})$ & \%Yield $\left({ }^{\mathrm{w}} / \mathrm{w}_{\mathrm{w}}\right)$ & Colour & Texture \\
\hline 1. & n- Hexane & 50.00 & 10.00 & green & gummy mass \\
\hline
\end{tabular}

Chromatographic Separation of Methanol

Leaf Extract of Senna siamea and of the Fractions

Column Chromatographic Analysis of Methanol Leaf Extract of Senna siamea

Components present in the methanol leaf extract of Senna siamea were separated through column chromatographic technique. Similar fractions were combined together and were coded: SSM (1a-1b) as 1, SSM (2a-2b) as 2, SSM (3a-5a) as 3, SSM (5b-6a) as 4 and SSM (6b-11b) as 5 . Percentage yields of the combined fractions determined ranged from $18.5 \%$ with fraction $\mathrm{SSM}_{5}$ as the highest, to $0.5 \%$ of $\mathrm{SSM}_{1}$ as the combined fraction with the lowest weight. The colours of the column fractions ranged from dark green of $\mathrm{SSM}_{1}$ to brown of $\mathrm{SSM}_{5}$

Thin Layer Chromatographic Analysis of the Column Fractions

The fractions collected from column chromatographic analysis were monitored by thin layer chromatographic technique. The combined column fractions encoded $\mathrm{SSM}_{4}$ and $\mathrm{SSM}_{5}$ did resolve while $\mathrm{SSM}_{1}, \mathrm{SSM}_{2}$ and $\mathrm{SSM}_{3}$ fractions didn't resolved when solvent system of toluene and n-butanol (4:1) was used. The recombined fractions of the spots observed were calculated using the equation below while values obtained are shown on Table 3.

$$
\text { Retardation factor }=\frac{\text { distance travelled by solute }(\mathrm{cm}) \text { from the origin }}{\text { distance moved by solvent }(\mathrm{cm}) \text { from the origin }}
$$

Table 3: Fractions, weight of dried fractions, percentage yield of the recombined and colour of the fractions from column chromatographic analysis

\begin{tabular}{lccll}
$\begin{array}{l}\text { Recombined } \\
\text { fraction }\end{array}$ & $\begin{array}{c}\text { weight of dried } \\
\text { recombined fraction }(\mathbf{g})\end{array}$ & $\begin{array}{c}\% \mathbf{w}_{\mathbf{w}} \text { of recombined } \\
\text { fraction }\end{array}$ & Component & $\begin{array}{l}\text { Colour of } \\
\text { fraction }\end{array}$ \\
\hline $\mathrm{SSM}_{1}$ & 0.5 & 2.5 & $\mathrm{SSM}(1 \mathrm{a}-1 \mathrm{~b})$ & dark green \\
$\mathrm{SSM}_{2}$ & 0.6 & 3.0 & $\mathrm{SSM}(2 \mathrm{a}-2 \mathrm{~b})$ & green \\
$\mathrm{SSM}_{3}$ & 1.5 & 7.5 & $\mathrm{SSM}(3 \mathrm{a}-5 \mathrm{a})$ & dark brown \\
$\mathrm{SSM}_{4}$ & 0.7 & 3.5 & $\mathrm{SSM}(5 \mathrm{~b}-6 \mathrm{a})$ & light brown \\
$\mathrm{SSM}_{5}$ & 3.7 & 18.5 & $\mathrm{SSM}(6 \mathrm{~b}-11 \mathrm{~b})$ & brown
\end{tabular}

Initial weight of crude aqueous extract $=20 \mathrm{~g}$, Amount recovered $=7.0 \mathrm{~g}$, Percentage recovered $=35 \%$ $(\mathrm{w} / \mathrm{w}), \mathbf{S S M}=$ Senna siamea methanol extract, Mobile phase $=$ toluene and butanol $(4: 1)$

Re-Chromatographic Separation of Methanol Leaf Extract of Senna siamea of the portion 5 fractions

Components present in the methanol leaf extract of Senna siamea were fractionated using micro column with silica gel $30 \mathrm{~g}$ and the silica gel as stationary phase and $3.7 \mathrm{~g}$ of the extracts, while toluene and n-butanol at different increasing polarity ratio were used as the mobile phase. Fractions were coded: $\operatorname{asSSM}_{51} \mathrm{SSM}_{52}, \mathrm{SSM}_{53}$, $\mathrm{SSM}_{54}$ and $\mathrm{SSM}_{55}$. Weights of the combined fractions determined ranged from $24.86 \%$ with fraction $\mathrm{SSM}_{54}$ as the highest, to $5.68 \%$ of SSM 52 as the combined fraction with the lowest weight.

Thin Layer Chromatographic Analysis of the Column Fractions

The fraction from column chromatographic analysis was monitored by thin layer chromatographic technique. The column fractions encoded did not resolve while $\mathrm{SSM}_{5}$ fractions resolved when solvent system of 
toluene and butanol was used. The retardation factors of the spots observed were calculated using the equation below while values obtained are shown on Table 4.

$$
\text { Retardation factor }=\frac{\text { Distance travelled by solute }(\mathrm{cm}) \text { from the origin }}{\text { Distance moved by solvent }(\mathrm{cm}) \text { from the origin }}
$$

Table 4: Recombined fractions, weight of dried recombined fraction, percentage yield from portion $\mathrm{SSM}_{5}$ column chromatographic analysis

\begin{tabular}{lccc}
\hline $\begin{array}{l}\text { Recombined } \\
\text { fraction }\end{array}$ & $\begin{array}{c}\text { Weight of dried } \\
\text { recombined fraction }(\mathbf{g})\end{array}$ & $\begin{array}{c}\text { \% (w/w) of recombined } \\
\text { fraction }\end{array}$ & Component \\
\hline $\mathrm{SSM}_{51}$ & 0.35 & 9.45 & 1 \\
$\mathrm{SSM}_{52}$ & 0.21 & 5.68 & 2 \\
$\mathrm{SSM}_{53}$ & 0.12 & 3.24 & 3 \\
$\mathrm{SSM}_{54}$ & 0.80 & 21.62 & 4 \\
$\mathrm{SSM}_{55}$ & 0.28 & 7.57 & 5 \\
\hline
\end{tabular}

Initial weight of crude aqueous extract $=3.7 \mathrm{~g}$, Amount recovered $=1.76 \mathrm{~g}$, Percentage recovered $=47.56$ $(\mathrm{w} / \mathrm{w}), \mathbf{S S M}=$ Sennasiemea methanol extract, Mobile phase $=$ Toluene and $\mathrm{n}$-butanol

Table 5: Thin layer chromatographic (TLC) profile of the column fractions of methanol leaf extract of Senna siamea

\begin{tabular}{lllcl}
\hline $\begin{array}{l}\text { Fraction } \\
\text { Factor }\left(\mathbf{R}_{\mathbf{f}}\right)\end{array}$ & Colour of fractions & No. of spot & Distance $(\mathbf{c m})$ & Retardation \\
\hline & pale yellow & NR & & \\
2 & yellow & NR & & \\
3 & yellow & NR & 12.5 & 0.71 \\
4 & yellow & 1 & 11.0 & 0.63 \\
5 & yellow & 2 & 8.6 & 0.51 \\
\hline
\end{tabular}

NR = Not Resolve, $\mathbf{S S M}=$ methanol leaf extract of Senna siamea, Solvent front $=17 \mathrm{~cm}$, Solvent system $=$ Toluene: n-butanol; 4:1

Ultraviolet-Visible spectroscopy of Fraction $\mathrm{SSM}_{54}$ of the Leaf Extract of Senna siamea

The result of the ultraviolet-visible spectroscopy of the isolated compound of the methanol leaf extract of Senna siamea is shown in Figures 1.The result of the UV-visible with a wavelength of $289 \mathrm{~nm}$ and the absorbance of 4.268 .

IR Spectroscopy of the methanol leaf Extract of Senna siamea of $\mathrm{SSM}_{54}$

Infrared spectroscopy is used to gather information about compound's structure, assess its purity, and sometimes to identify it. The infrared spectroscopy has a range of 4000-650 $\mathrm{cm}^{-1}$; the functional groups indentify are $\mathrm{O}-\mathrm{H}$, $\mathrm{N}-\mathrm{H}, \mathrm{C}-\mathrm{H}$ stretching group at $3385.8 \mathrm{~cm}^{-1}$, $\mathrm{CHO}$ at $2955.8 \mathrm{~cm}^{-1}$, -CHO stretching at 2926.0 $\mathrm{cm}^{-1},-\mathrm{NH}_{3}{ }^{+}$at $1640.0 \mathrm{~cm}^{-1}$, carboxylate ion $-\mathrm{CO}_{2}{ }^{-}$ for amino acid at $1449.9 \mathrm{~cm}^{-1},-\mathrm{N}=\mathrm{N}-$ at 1401.5 $\mathrm{cm}^{-1},-\mathrm{N}^{+} \mathrm{O}^{-}=\mathrm{N}-$ at $1315.8 \mathrm{~cm}^{-1}, \mathrm{C}-\mathrm{O}-\mathrm{C}$ at1 189 $\mathrm{cm}^{-1}$, Si-O at $1084 \mathrm{~cm}^{-1}$ and $\mathrm{S}=\mathrm{O}$ at 1013.8 table 4.8 show the function assign to the values obtain from the IR. Figure 2 the IR chart 


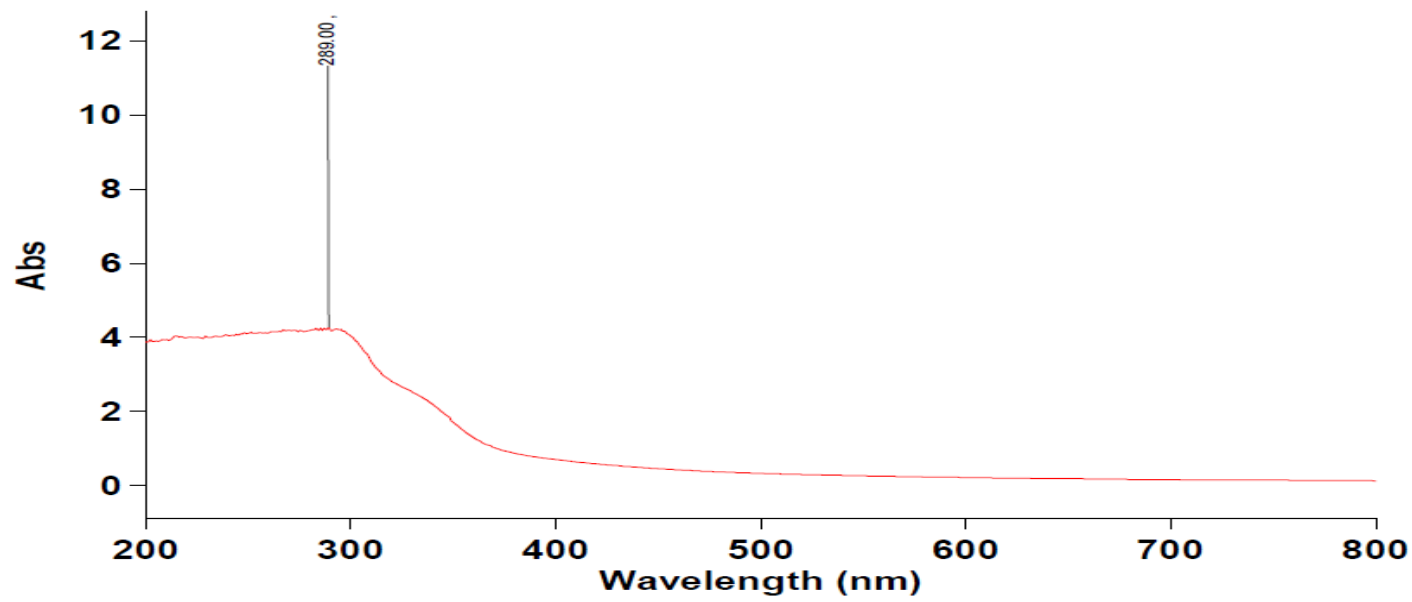

Figure 2: The UV spectra of fraction $\mathrm{SSM}_{54}$ of the leaf extract of Senna siamea showing the Aborbance

Table 6: Infra- red values of functional groups indentified it various frequencies of Senna siamea fraction $\mathrm{SSM}_{54}$

\begin{tabular}{lll}
\hline S/N & Wavelengths & Functions \\
\hline 1 & 3385.8 & $\mathrm{O}-\mathrm{H}$ \\
2 & 2955.8 & $-\mathrm{CHO}$ \\
3 & 2926.0 & $-\mathrm{CHO}$ \\
4 & 1640.0 & $-\mathrm{NH}_{3}^{+}$ \\
5 & 1449.9 & $-\mathrm{CO}_{2}^{-}$for amino acid \\
6 & 1401.5 & $-\mathrm{N}=\mathrm{N}-$ \\
7 & 1315.8 & $-\mathrm{N}^{+} \mathrm{O}^{-}=\mathrm{N}-$ \\
8 & 1189.0 & $\mathrm{C}-\mathrm{O}-\mathrm{C}$ \\
9 & 1084.7 & $\mathrm{Si}-\mathrm{O}$ \\
10 & 1013.8 & $\mathrm{Si}=\mathrm{O}$ \\
\hline
\end{tabular}

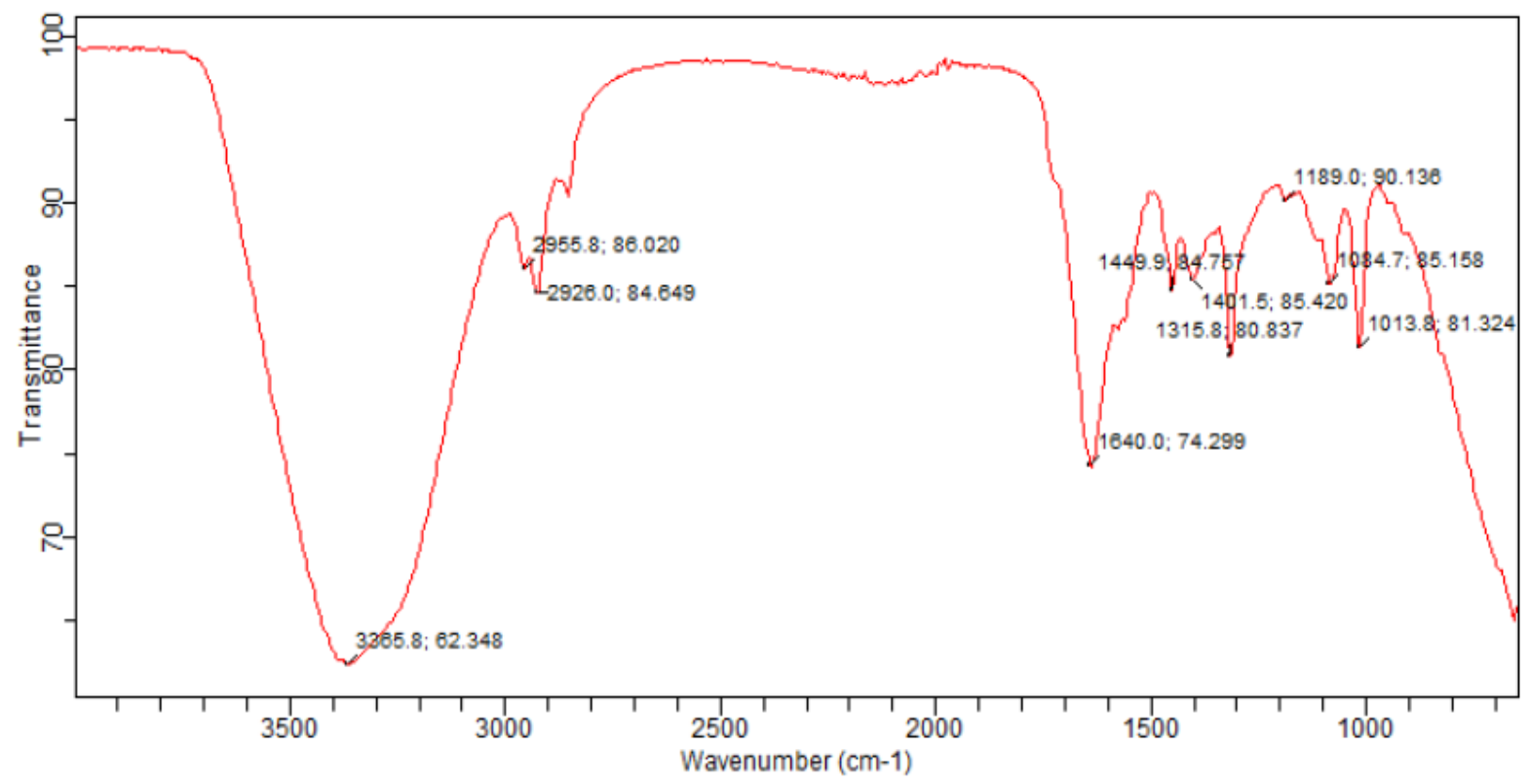

Figure 3: Infra red spectrum of methanol leaf extract of Senna siamea SSM $_{54}$ 


\section{Gas Chromatography-Mass Spectroscopy (GC-MS) of Fraction $\mathrm{SSM}_{54}$ of the Leaf Extract of Senna siamea}

The gas chromatography-mass spectroscopy of the isolated compound of the $\mathrm{SSM}_{54}$ methanol leaf extract of Senna siamea is shown six (6) peaks with the major peaks, retention time, area and library ID. Peak number 6 , the retention time 32.727 , the area 18333446.22 and the library ID Diisoctyl phthalate figure 4 shows the compound, peak number 5 , retention time 22.765 , the area 458490.25 and the library ID Purine-2,6-dione, 8-(3-Ethoxypropylamino)-1,3dimethyl-3, 9-dihydro- figure 5, peak number 4, retention time 9.302, the area 402059.29 and the library ID a-Pinene, 10-(dimethylaminomethyl) figure 6 , peak number 3 , retention time 8.735 , the area 250535.49 and the library ID $1 \mathrm{H}-$ indene-2-ethanamine, N, N- dimethyl-3-[1-(2pyrindinyl)ethyl]- figure 7 , peak number 2 , retention time 8.449 , the area 51617.52 and the library ID Benzene, 1, 2- bis(2,5dimethylphenylaminomethyl)-3,6- dimethylfigure 8 and peak number 1 , retention time 9.302, the area 402059.29 and the library ID Cinnamic acid, p-(trimethylsiloxy)-, methyl ester figure 9

Figure 4 shows the chromatogram of the sample $\mathrm{SSM}_{54}$. Clear peaks (levels) were marked out for analysis by the mass spectrometer.

Table 8 shows the $\%$ area, retention time, peak number, and quality of peaks of the gas chromatogram of fraction $\mathrm{SSM}_{54}$. Peak 22 has the highest \% area of 32.90 .

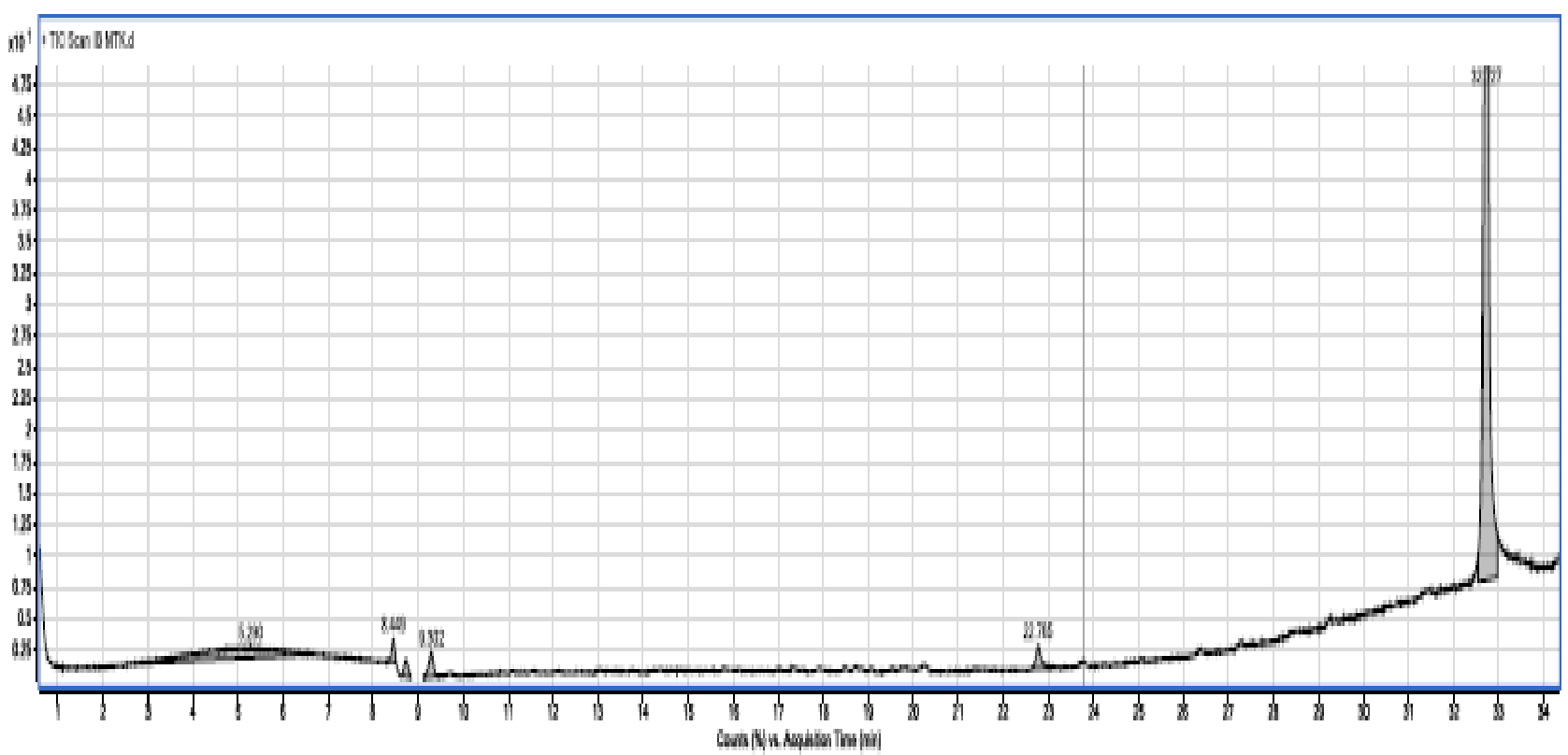

Figure 4: Gas chromatogram of leaf extract of fraction $\mathrm{SSM}_{54}$

Table 8: Gas Chromatographic analysis of fraction $\mathrm{SSM}_{54}$ methanol leaf extract of Senna siamea

\begin{tabular}{lllcl}
\hline Peak No. & Retention Time & \%Area & height & width \\
\hline 1 & 5.29 & 2986873.63 & 24062.06 & 8.638 \\
2 & 8.449 & 241574.50 & 51617.52 & 0.175 \\
3 & 8.735 & 250535.50 & 38455.00 & 0.209 \\
4 & 9.305 & 402059.29 & 56016.94 & 0.307 \\
5 & 22.765 & 458490.25 & 52317.93 & 0.452 \\
6 & 32.727 & 18333446.22 & 2620877.88 & 0.418 \\
\hline
\end{tabular}


Table 9: Gas chromatography-Mass spectroscopy analysis of isolated compound from $\mathrm{SSM}_{54}$

\begin{tabular}{|c|c|c|c|c|c|}
\hline Peak no & $\begin{array}{l}\text { Retention } \\
\text { Time (min) }\end{array}$ & $\begin{array}{l}\text { Name of } \\
\text { Compound }\end{array}$ & $\begin{array}{l}\text { Molecular } \\
\text { Formular }\end{array}$ & Mol. W & $\begin{array}{c}\% \\
\text { Area }\end{array}$ \\
\hline 1 & 5.29 & $\begin{array}{l}\text { Cinnamic acid, } \\
\text { p-(trimethylsiloxy)- } \\
\text { methyl ester Oxide }\end{array}$ & $\mathrm{C}_{9} \mathrm{H}_{8} \mathrm{O}$ & 148 & 2986873.63 \\
\hline 2 & 8.45 & $\begin{array}{l}\text { Benzene, } 1,2 \text { - bis } \\
\text { (2,5-dimethylphenyl } \\
\text { aminomethyl)-3,6- } \\
\text { dimethyl- undecene }\end{array}$ & $\mathrm{C}_{26} \mathrm{H}_{32} \mathrm{~N}_{2}$ & 372 & 241574.50 \\
\hline 3 & 8.74 & $\begin{array}{l}\text { 1H-indene-2-ethanamine, } \\
\mathrm{N}, \mathrm{N} \text { - dimethyl-3-[1-(2- }\end{array}$ & , $\mathrm{C}_{20} \mathrm{H}_{24} \mathrm{~N}_{2}$ & 292 & 250535.49 \\
\hline 4 & 9.30 & $\begin{array}{l}\text { pyrindinyl)ethyl]-a-Pinene } \\
10 \text { - (dimethylaminomethy }\end{array}$ & $\begin{array}{l}\text { e, } \mathrm{C}_{13} \mathrm{H}_{23} \mathrm{~N} \\
\mathrm{yl})\end{array}$ & 193 & 402059.29 \\
\hline 5 & 22.77 & $\begin{array}{l}\text { Purine-2,6-dione, 8-(3- } \\
\text { Ethoxypropylamino)-1,3- } \\
\text { dimethyl-3, 9-dihydro- }\end{array}$ & $\mathrm{C}_{12} \mathrm{H}_{19} \mathrm{~N}_{5} \mathrm{O}_{3}$ & 281 & 458490.25 \\
\hline 6 & 32.73 & Diisooctyl phthalate & $\mathrm{C}_{24} \mathrm{H}_{38} \mathrm{O}_{4}$ & 390183 & 33446.22 \\
\hline
\end{tabular}<smiles>COC(=O)/C=C/c1ccc(O[Si](C)(C)C)cc1</smiles><smiles>Cc1cc(C)cc(NCc2ccccc2CNc2cc(C)cc(C)c2)c1</smiles>

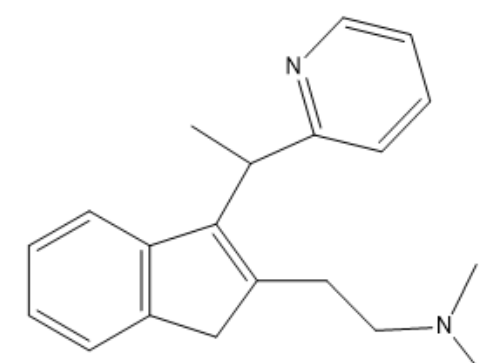

Fig 7: 1H-indene-2-ethanamine, N, N-dimethyl-3-[1-( pyrindinyl)ethyl

Fig 6: Benzene, 1,2-bis(2,5-dimethylphenyaminoethyl)-3,6-demethyl

Fig 5: Cinnamic acid, p-(trimethylsiloxy)-, methyl ester
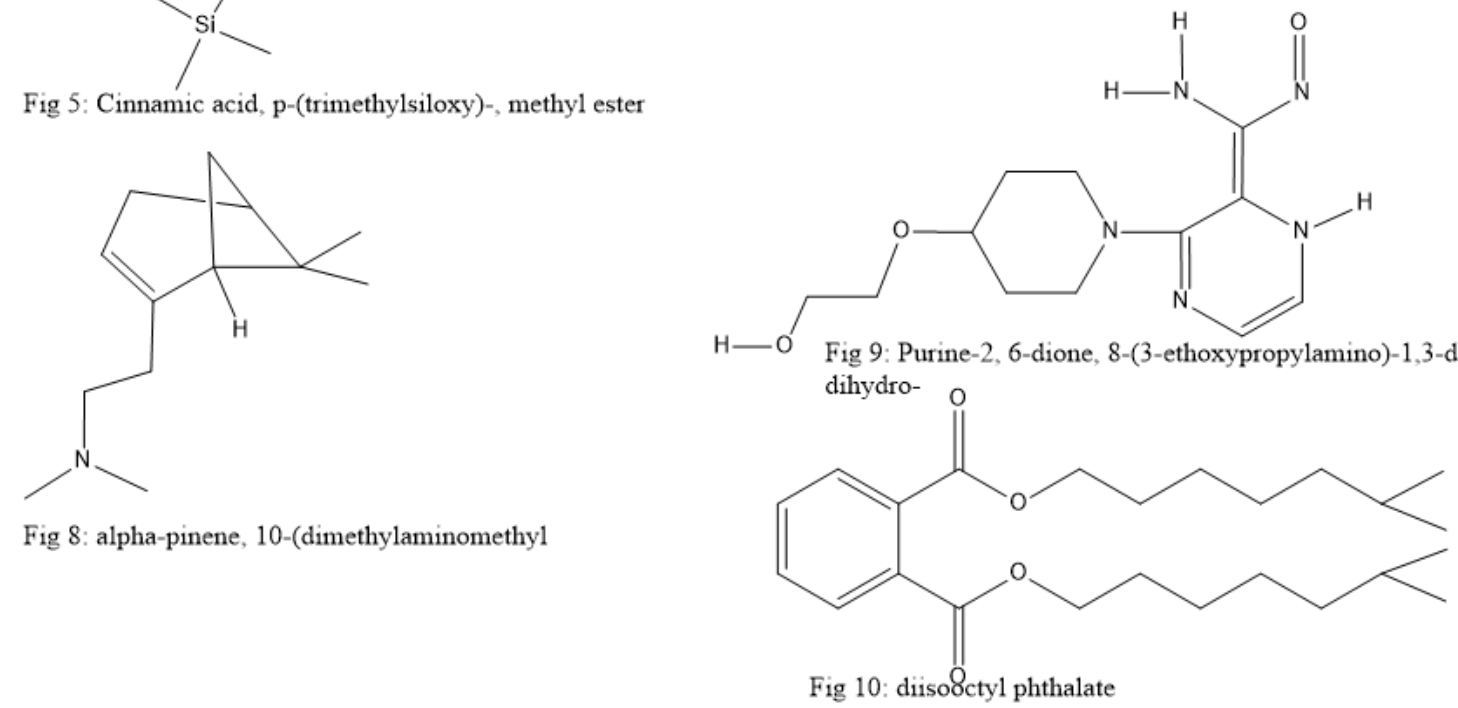

The structure of the compounds isolated from GC-MS analysis of $\mathrm{SSM}_{54}$ 


\section{DISCUSSION}

The value obtained for the sub fraction of $\mathrm{SSM}_{54}$ methanol leaf extract of Senna siamea UV the result is in support of Ultraviolet Detection of Monosaccharides: Multiple Wavelength Strategy to Evaluate Results after Capillary Zone Electrophoretic Separation [9].

Results of the IR spectra of fraction $\mathrm{SSM}_{54}$ had values of the functional groups indentified as follows: $\mathrm{O}-\mathrm{H}, \mathrm{N}-\mathrm{H}, \mathrm{C}-\mathrm{H}$ stretching group at $3385.8 \mathrm{~cm}^{-1},-\mathrm{CHO}$ at $2955.8 \mathrm{~cm}^{-1},-\mathrm{CHO}$ stretching at $2926.0 \mathrm{~cm}^{-1},-\mathrm{NH}_{3}{ }^{+}$at $1640.0 \mathrm{~cm}^{-1}$, carboxylate ion $-\mathrm{CO}_{2}^{-}$for amino acid at $1449.9 \mathrm{~cm}^{-1},-\mathrm{N}=\mathrm{N}-$ at $1401.5 \mathrm{~cm}^{-1},-\mathrm{N}^{+} \mathrm{O}^{-}=\mathrm{N}-$ at $1315.8 \mathrm{~cm}^{-1}$, C-O-C at1189 $\mathrm{cm}^{-1}$, Si-O at 1084 $\mathrm{cm}^{-1}$ and $\mathrm{S}=\mathrm{O}$ at 1013.8 .

The successful separation of biomolecules by the chromatographic technique depended upon suitable solvent system which needs an ideal range of partition coefficient $(\mathrm{K})$ for each target compound [10].

Result of GC/MS analysis of sub-fraction $\mathrm{SSM}_{54}$ of the methanol leaf extract of Senna siamea indicate the compound Diisooctyl phathalate in the extraction and bioactivity from Jatropha curcas $L$. and also in Diisooctyl phthalate in plantago major $L$. reported the presence of this compound [11, 12]. Research indicates that diisooctyl phthalate has antimicrobial and algicidal activities as reported by [13], Purine-2, 6-dione, 8-(3-Ethoxypropylamino)-1, 3dimethyl-3, 9-dihydro- was report by [14] in GC-MS analysis.

\section{Reference}

1. M. Tsivou, N. Kioukia-Fougia, E. Lyris, Y. Aggelis, A. Fragkaki, X. Kiousi, P. Simitsek, H. Dimopoulou, I. P. Leontiou, M. Stamou, M. H. Spyridaki, and C. Georgakopoulos, (2006), An Overview of the Doping Control Analysis During the Olympic Games of 2004 in Athens, Greece. Analytica Chimica Act, 555, 1-13.

2. D. S. Fabricant, and N. R. Farnsworth, (2001). "The value of plants used in traditional medicine for drug discovery". Environmental. Health Perspectives, 109, 69-75.

3. A. Bruneau, M. Mercure, G. P. Lewis, and P. S. Herendeen, (2008),
Phylogenetic patterns and diversification in the caesalpinioid legumes, Botany, 86, 697-718.

4. D. Cardoso, R. T. Pennington, L. P. De Queiroz, J. S. Boatwright, B. E. Van Wykd, M. F. Wojciechowskie, and M. Lavin, (2013), Reconstructing the deepbranching relationships of the papilionoid legumes, South African Journal of Botany, 89: 58-75.

5. B. Marazzi, P. K. Endress, L. P. Queiroz, and E. Conti, (2006), Phylogenetic relationships within Senna (Leguminosae, Cassiinae) based on three chloroplast DNA regions: patterns in the evolution of floral symmetry and extrafloral nectaries, American Journal of Botany, 93, 288-303.

6. M. H. Laurence, and J. M. Christopher, (1989), Experimental Organic Chemistry: Principles and Practice (Illustrated Edition), Wiley Blackwell, pp. 180-185.

7. S. M. K. Rates, (2001), Review, Plants as source of drugs, Toxicology, 39, 204 $-207$.

8. E. Stahl, (2005), Thin Layer Chromatography, A Laboratory Handbook. 2nd ed., Springer (India); Pvt., Ltd., pp, 53-56.

9. L. Kaijanen, M. Paakkunainen, S. Pietarinen, E. Jernström, S. Reinikainen, (2015) Ultraviolet Detection of Monosaccharides, Multiple Wavelength Strategy to Evaluate Results after Capillary Zone Electrophoretic Separation, International Journal of Electrochemical Science, 6, 2950-2961.

10. Y. Ito, (2005), Golden rules and pitfalls in selecting optimum conditions for high-speed counter current chromatography, Journal of Chromatography A, 1065, 145-168.

11. D. A. Romeh, (2013), Diethyl Phthalate and DioctylPhthate in Plantago major $L$. African Journal of Agricultural Research, 8, 4360-4364pp.

12. L. Soto-Armenta, J. Sacramento-Rivero, A. Gonzalez-Coloma, G. MartinezSebastians, and A. J. Rocha-Uribe, (2019), Extraction and Bioactivity from 
Jatropa curcas $L$. leaves by Steam Distillation. Pakistan Journal of Botany, 51, 1-6pp

13. C. C. Bie, F. M. Li, Y. F Wang, H. Y Wang, Y. H Zhao, W. Zhao, and Z. Y. Wang, (2012), Mechanism of the inhibitory action of melochemicalDibutyl phthalate on
AlgeaGymnodiniumbreve, Environmental Science, 33, 228-232.

14. L. Razeghi, M. Azizi, S. M. Ziaratnia, A. Z. Bagheri, and S. H. Nemati, (2015) Evaluation in vitro culture of KelussiaodoratissimaMozaff and secondary metabolites production through suspension cultures, The Pharma Innovation Journal, 5, 74-80. 